\title{
The Mechanic Ear: North American Sound Poetry in the Digital Age
}

\author{
María GOICOECHEA \& Víctor SALCEDA \\ Universidad Complutense de Madrid \\ Departamento de Filología Inglesa II \\ mgoico@filol.ucm.es \\ victor.salceda.garcia@gmail.com
}

\begin{abstract}
This essay provides a revision of North American sound poetry from the perspective of the digital culture. In an effort to describe the role that sound plays in digital literature creations, we have tried to find points of suture between the practitioners of sound poetry of different decades and the contemporary practices of sound and digital poetry. The main objective is to establish a relation between these poetic genres, as they both emphasize the aural dimension as well as challenge academic categorization and print tradition alike.

We discuss the work of three seminal practitioners of sound poetry: Jerome Rothenberg, John Cage, and Jackson Mac Low. We examine their proposals alongside those of contemporary artists that belong to what we describe as the posthuman phase of sound poetry: Jim Andrews, Christian Bök, and Tracie Morris. Through the comparison of seminal sound poetry practitioners of the 1960s with contemporary North American poets that have recuperated poetry's performative dimension, we explore the new poetical effects produced by the digitalization of the human voice alone or in combination with other sounds, images and text.

From Native American chants to the digital poetry found on the Web, we explore the influence of the medium as well as other cultural factors influencing the production of oral poetry and its dissemination. Digital poetry nourishes itself from previous literary traditions as well as from the multimedia convergence favoured by the digital medium.

Despite being latecomers to the field of sound poetry, North American sound poets have influenced the work of artists at a global level, and continue to do so, both through their digital creations and through their live performances.
\end{abstract}

Keywords: sound poetry, sound art, digital poetry, concrete poetry, spoken word, John Cage, Richard Kostelanetz, Jackson McLow, Jerome Rothenberg, Jim Andrews, Christian Bök, Tracie Morris.

[T] he world is not for the beholding. It is for hearing. It is not legible, but audible.

Jacques Attali, Bruits (1977)

\section{INTRODUCTION}

"You are what you listen to," runs the slogan of the radio station we listen to everyday, reminding us of the nourishing and constituent nature of ubiquitous sound, 
of its inexorable power to penetrate deep layers of our psyche and imperceptibly construct our identity. No artist will miss the opportunity to exploit this potentiality and yet it is not always an aspect that captures the critic's attention. Despite the fact that the sound dimension is essential to all kinds of poetry, it has probably been its most neglected feature. As researchers of digital literature and contemporary North American poetry, we have wondered about the role that sound plays in digital literature creations, now that artists have an incredible range of multimedia effects at their disposal. To tune our ears for the study of sound in particular, we have turned our magnifying glass upon a field of artistic experimentation that has made of the exploration of sound its raison d'être: sound poetry.

While studying digital poetry, it became obvious that visual poetry experimentation, for example, had continued to develop with digital technology. What we found somewhat less exploited was the connection between the experiments of previous generations of sound poets and those of digital poets. Our approach has been to trace a genealogy that would connect American sound poetry of the past with the new creations to be read on the screen and beyond. This task has the double function of developing the field of digital literature's antecedents and of exploring, through the proposals of sound artists, the realm of sound in its purest, most abstract level.

It seems to us that we find ourselves at a vantage point to reflect on sound poetry: We are now living in the highly technologized world envisioned by the futurists, the fathers of contemporary sound poetry. Today artists have at their disposal a vast array of machines to experiment with sound, at the same time that sound technology has also become a central element in our quotidian life. We have become intimately fused with the machine, we are hybrid monsters, Haraway's cyborgs, whose sounds are being everyday mediated, transformed, and extended by the machine. Mobile phones, for instance, have become the most precious and indispensable of all our technological extensions; we use them to talk, read and write messages, produce images, but also to select our own particular soundscape. We suspect the effect of sound is probably even more perturbing than that of the image, since it has the ability to reach deep spaces in our psyche, often without our conscious validation. But what kind of changes, interferences, "massages"1 does sound perpetrate? We have the naïve hope that the twenty-first century sound poetry will prove to be the ideal artistic vehicle to reflect on these transformations in an incisive way, but whether the sound art avant-garde is just another commodity to help masquerade our emptiness, or if, on

${ }^{1}$ McLuhan (1964) challenged conventional definitions when he claimed that the medium is the message, and that the medium is the massage, implying that media is mainly used to anesthetize our consciousness. With this claim, he stressed how channels differ, not only in terms of their content, but also in regard to how they awaken and alter thoughts and senses. He distinguished media by the cognitive processes each required. McLuhan popularized the idea that channels are a dominant force that must be understood to know how the media influence society and culture. 
the other hand, it represents opposition, confrontation, plausible alternatives to the grinding mill of hypercapitalism, it is left to the reader to conclude.

If we have placed such high expectations in sound poetry is because it belongs to a minority genre in the periphery of the literary establishment, and as such, it can enjoy a greater creative freedom than other, more consecrated, literary genres. This subaltern status is, for the moment, also shared with electronic literature. We perceive, however, that new, potent synergies between the field of literature and digital technologies are transforming the literary ecology, the construction of the canon, the centre and the margins of a field that is reinventing its history, its genealogy, to account for new practices, to accommodate them within its tradition. So it happens that minority genres such as poetry become the centre of the new paradigm introduced by electronic literature. This new category has behaved like many other avant-garde literary movements of the past, largely ignored by the general public, and well-known only to a small clique of creators and critics. What makes this avantgarde specially relevant for us today is that it represents the spearhead of modes of creation and reception that will become generalized in the years to come, from ways of reading to modes of writing and performing artistic works.

Moreover, with the advent of digital technology we have a great tool, on the one hand, for creating, archiving and disseminating sound works, and, on the other, for unexpected readers finding such material and studying it from a wide variety of perspectives. In our case, we have tried to ascertain the existence of idiosyncratic traits in North American sound art and we have tested their endurance and evolution through time. The distinctive features that have been identified revolve around tendencies that have oft-times served to separate American intellectual culture from European (with Canadian culture often aligned with the European): its flight from an excessively formalistic or intellectualized ideological stratum for its art, its capacity for creating a potent syncretism of a rich variety of influences, and the pivotal role played by technology to both create strong alliances or rejection as it interacts with the polar forces of American pastoralism (see Scheese 2002 and Sayre 2013). We found this last feature to be an interesting point of departure and we have articulated our essay around it.

Attitudes versus the impact of technology in human life have polarized artists in America in a distinctive way, making technology a central theme, for either technophilic or Luddite sound poets. We have found that some of the most influential American sound poets are less technologically oriented than its European counterparts, nevertheless their concerns have also placed technology at the core of their work, becoming referents for generations of poets after them. We have chosen to detain ourselves in the work of three seminal practitioners of sound poetry: Jerome Rothenberg, John Cage, and Jackson Mac Low. We will examine their proposals alongside those of contemporary artists that belong to what we will describe as the posthuman phase of sound poetry: Jim Andrews, Christian Bök, and Tracie Morris. Despite being latecomers to the field of sound poetry, North American sound poets 
have influenced the work of artists at a global level, and continue to do so, both through their digital creations and through their live performances.

For our study, we have mainly gathered information from these four webpages:

1. Ubuweb, an avant-garde magazine founded by poet Kenneth Goldsmith.

2. The Sound Poetry section of the Electronic Poetry Center at Buffalo University (which mainly guides you through the massive amount of material of Ubuweb).

3. Penn Sound Webpage.

4. The Electronic Literature Directory.

We have used these sources to find a genealogy between different generations of North American poets, digging at the roots of sound poetry experimentation in order to trace its evolution. In this process, we have come across an important obstacle, which is the diffuse delimitations between art categories and genres, especially within the field of sound performance. So before continuing, let us discuss the problem of genre definition.

\subsection{DEFINING SOUND POETRY}

Experimentation in the field of sound poetry is characterized by different attempts to underscore, isolate for analysis, the sonority of language and the power of sound for communication. The results might appear too playful, humorous, or plain trivial, but under the surface lies a deep concern and reflection about the potentialities of sound art for expanding the range of resources artists have beyond reference and semantic representation; for exploring the spectrum of vocal expression beyond language, beyond music. As Richard Kostelanetz has observed, "text-sound art," as he calls it, "is an intermedium located between language arts and musical arts," it subjects an aural text to modifications more typical of music but its raw material is linguistic, its basic unit being a "vocable," which he defines as "a word regarded as a unit of sounds or letters rather than a unit of meaning" (1). Therefore, we could say that sound poetry is not just merely a type of poetry that places the emphasis on sound effects but it is an experimental form of poetry whose boundaries sometimes intersect with other types of art such as visual poetry, performance art, conceptual art and music.

We could classify sound poetry pieces with respect to their mode of transmission and their relation to a notation, medium or code. A large percentage of contemporary sound poems are dependent more or less freely on a score, some can exist independently of their live performance and others are inextricably tied to the time and space of their staging. We will see later how digital technology intersects with previous modes of representation and reception, amplifying potentialities and exponentially increasing technical complexity. 
In the digital domain, sound poetry is often represented in some graphic form, which keeps many similarities de facto with visual poetry; however, its purpose is to allude to the aural dimension more than the visual. Jim Andrews, a visual and sound poet working primarily on the web, has written: "As sound poetry is to spoken poetry, so is visual poetry to written poetry, often” (2001), meaning that the spoken (recited) poetry is a different genre from sound poetry. We could equally say that visual poetry explores aspects not included in written poetry (a form of poetry mainly created to be read or recited not just merely "seen"), sound poetry is meant to be heard at a deep, primal level, very often going beyond structures of meaning, and playing directly on the emotional cords. It differentiates itself from the spoken word genre in the same way that figurative painting differs from abstract painting. In its most radical representations, sound poetry can limit itself to a study of pure noise and silence, the first binary language from which all others emerged.

In practice, sound poets have adopted a wide range of techniques, many of which depend on a single idea which is exploited throughout the piece and which introduces a defamiliarization effect: through repetition, non-sense, polyphony, invented languages, noise, voice transformation, onomatopoeia, synthetic sound, or a mixture of several resources. The choice of experimental modes has varied in the course of sound poetry's intermittent and diffuse development, and there can be identified different stages which have been influenced by historical, social, cultural, and technological contexts. As in most forms of contemporary art the context and discourse surrounding the piece are essential for its interpretation, and sound poetry is no exception: "It is a kind of inferential art" writes Kostelanetz, "whose impact depends upon the audience's contextual awareness of the work's origins and purposes" (1980).

\subsection{ORIGINS}

Sound poetry is mainly a contemporary creation. It can be traced back to the end of the nineteenth century and the beginning of the twentieth century, in Futurist and Dadaist experimentation with language's acoustic properties beyond semantic representation. It is then that artists become self-conscious of the singularity of their attempt and compete in being the "first" to play with an original constriction (a poem without words, a poem made of howls, noises, onomatopoeias, artificial languages, etc.). However, as we will see later, it is important not to leave completely aside primitive oral traditions or even children linguistic games and exploration, for example, since many of sound poetry's resources find their origin there. Actually, as sound poet and critic, Steve McCaffery has observed:

[T] he very attempt to write a history of sound poetry is a doomed activity from the very outset. For one thing, there is no "movement" per se, but rather a complex, often 
oppositive and frequent antithetical interconnectedness of concerns-attempts to recover lost traditions mix with attempts to effect a radical break with all continuities. What is referred to as "sound poetry" is a rich, varied, inconsistent phonic genealogy. (1978)

Nevertheless, we can remit the reader to several in-depth surveys that have attempted such activity with success, and which have delineated the historical and cultural evolution of such a diffuse genealogy, including McCaffery's own essay and others (Higgins 1980, Kostelanetz 1980, McCaffery 1978). More recently, sound poetry has received renewed attention in Perloff and Dworkin's volume The Sound of Poetry/The Poetry of Sound (2009).

To sum up, we could distinguish four stages in the development of sound poetry: a pre-history, a coming-of-age, an adult phase and a post-human one. As we will see, in its latest forms, sound poetry cannot be divorced from the technological entourage that sustains it. The first stage, from archaic poetry to the experiments of the Futurists, represents a pre-history of sound poetry which encompasses an assorted range of primitive poetic and folkloric expressions that emphasized the sound dimension, to the detriment of meaning, as the repetitive structures of chants and incantation, the non-sense utterings and lexical distortions of shamans, nursery rhymes, and a series of isolated attempts by pioneer writers, such as Lewis Carroll and his "Jabberwocky".

The second phase, which builds up around the time of the First World War, has been recognized as the coming-of-age of a genre whose practitioners take to be more than a language-game and which, therefore, should be taken into serious consideration.

A reference work of sound poetry of this second stage is Zang Tumb Tumb written by Filippo Tommaso Marinetti, an Italian futurist, in 1914.
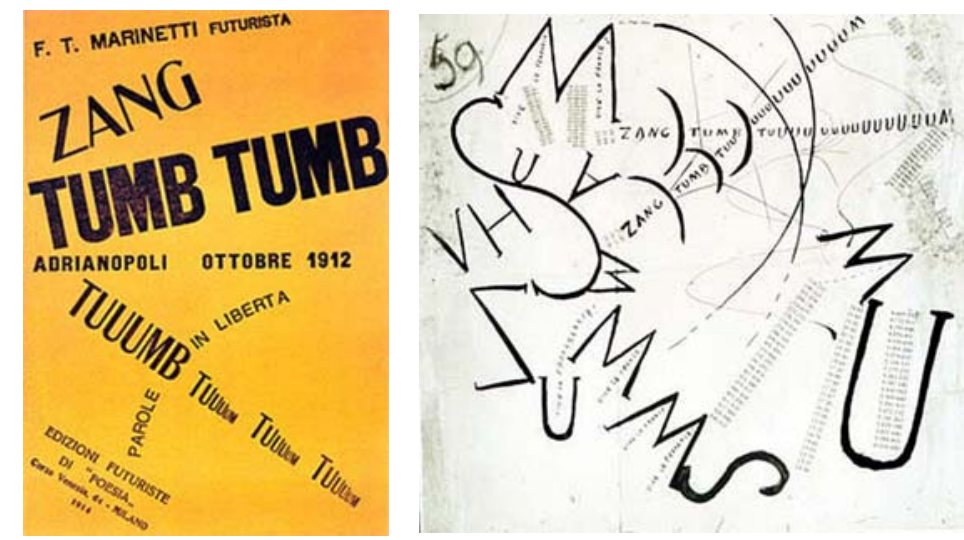

Figs. 1 \& 2: Cover (left) and interior page entitled "Vive la France” (right) of Zang Tumb Tumb by F.T. Marinnetti (1914). 
As you can see in the cover of his book, Marinetti used different fonts and typefaces, graphic arrangements and letter sizes to describe the battle of Adrianople, which he witnessed first-hand as a war reporter. His discovery of a formula that would serve as a sound poem notation establishes the connection between sound poetry and visual poetry, since the artist plays with the materiality of language, its disposition over the space of the page, as a way to transcribe the sounds, volumes, speed and rhythm of his poem. The onomatopoeias, the isolation of phonemes, the chaotic use of space, the break of linearity, the use of the diagonal, the circular and the vertical line, provide the graphic representation of the sound poem with a plasticity that equates it with the field of painting.

Marinetti's "Manifesto of Futurism," together with his ideas regarding "Words-inFreedom," transmitting art through the mass media and the writer's alliance with the machine, has many elements in common with today's use of the Internet, the importance of graphic design, and the computer as a writer's assistant. As Marinetti defended: "Deep changes in technology and science and in concepts of time and space called for the reinvention of all the arts, including music and literature" (Perloff 2009: 106). Like Whitman singing to the "body electric," sound poets also felt the need to radically express their reaction to human suffering and exploitation, not by roaming alone in the fields in mute contemplation of nature, but by establishing a dialogue with their most immediate experience of human alienation, which they perceived had been inexorably altered by the human-machine interface.

Facing Europe's state of devastation and existential vacuum, previous forms of literature seemed blunted, mute, and inefficient. Another sound poetry precursor, the Dadaist Hugo Ball, composed the first phonetic poem or "verse without words," "Karawane." The process of distillation of the poem to its minimum units of meaning reached the edge of meaning and went beyond it, in an effort to explore the unconscious through the sound manipulations of the human voice, musical composition and pure noise. This can be perceived as a logical consequence of the progressive mistrust versus language's capacity to manipulate thought through linguistic mediation, etc. As Henry Chopin makes explicit in his essay "Why I am an Author of Sound Poetry and Free Poetry":

The Word is useful no more; it even becomes an enemy when a single man uses it as a divine word to speak of a problematic god or of a problematic dictator. The Word becomes the cancer of humanity when it vulgarizes itself to the point of impoverishment trying to make words for all, promises for all, which will not be kept, descriptions of life which will be either scholarly or literary which will take centuries to elaborate upon with no time left for life. (1967: 2)

In synchronicity with their own cultural environment, sound poets also drew upon the developments of abstract painting and music, adapting this aesthetics to their field, a movement already envisioned by artists such as Wassily Kandinsky and Kurt 
Schwitters. Nevertheless, even in its avoidance or disintegration, the word remained as a point of reference, as Steve McCaffery reflects: "So word persists even in the state of its own ex-communication throughout the century." As he explains, up to the apparition of the tape recorder, which marks the beginning of sound poetry's third stage, what sound poetry did was "to render semantic meaning transcendental, as the destination arrived at by the disautomatization of sound perception" (1978). Therefore, words and their trail of meaning were actually enhanced by the very methods of "estrangement" that displaced them, providing a new perspective from which to look at their primal function within language.

We could also find a root to such experiments in the revival of oriental mysticism and its ideas regarding the false association between the ego and the wanderings of one's mind, fixed in language, as the cause of suffering. It stressed the need to dissociate one's self from the mind, its endless production of thoughts, and the language of internal discourse. As a logical consequence, sound poets deviated from poetry's main literary convention, such as its connection with the lyric, where the poem stands as a manifestation of an internal dialogue, ultimately a form of subjectivity. It was definitely not literature for the masses, as it was the paradoxical case of many modernist experiments, even if they had a different aim. Thus, the peripheral condition of such experiments is obvious, even though they remained highly influential in the artistic sphere, setting the stage for many provocative forms of art, especially in connection with concrete poetry and the concrete music movement.

The 1950s and 1960s, decades that can be considered the "adult" stage of sound poetry, see the proliferation of sound poetry experimentation around the possibilities introduced by the tape recorder. More than any other device, the use of the tape recorder and the amplifier mark the development of this period, with a myriad of European artists discovering the potential of this fusion with the machine. For the first time, the common availability of the tape recorder allowed artists to separate voice from speech, change the tone and speed of their voice, record, cut and paste strands of sound, overdub, mix human sound with environmental noises, etc. The tape recorder allowed for the transcendence of the human body. However, as it had been the case with Futurist and Dadaist experiments, the body became the focus of many of these sound pieces. Hear, for example, Henri Chopin’s "audiopoems": "L'énergie du sommeil” (1965), his series entitled "Le Corps” (1966), or “La Digestion” (1972). By recording visceral and mechanic body sounds, such as breathing while sleeping, and intertwined them with created and environmental sound, the body is transcended and placed besides other noise-making objects of the world, provoking a strange and captivating experience.

This capacity for recording sound and dislocating its production from its time and place has paradoxically projected a spotlight over the concept of performativity. The tape liberates composition from real time performance, it can serve as another encrypting technique or writing technology, but its pieces are incomplete until 
performed live in front of an audience that can invest them with the appropriate reception, whose perception is oriented towards questions that have to do with meaning and experience rather than the attestation of mere background noise. Performativity and audience response will be essential features in the work of sound poets.

\section{SOUND POETRY IN AMERICA.}

Sound poetry's reception in North America, given its cultural preferences, must ultimately account for the peculiarities of American pieces and establish its distinctive features with respect to European productions. Trying to identify North American sound poetry's distinctive qualities, artists have pointed out, for example, that most American sound poetry falls within the category of performative, improvisatory sound poems without a text. With the exception of Jackson Mac Low, Richard Kostelanetz and Charles Stein's so-called anti-formalism, it has been argued that "American literature tends to be aesthetically naïve by comparison to European (and Canadian) works" (Higgins 1980); that American practitioners "pursue a nonspecialist line," since they prefer to integrate sound poetry within more conventional concerns (McCaffery 1978); or that the dividing line between North American and European sound poets lies in the use of electronic machinery, which in the case of Americans polarized artists; some practitioners became either more technologically oriented than their European counterparts or far less (Kostelanetz 1980).

What we contend is that both strands of North American sound poetry experimentation, the naïve and the aesthete, the technophilic and the Luddite, have been crucial for the development of both digital poetry and subsequent generations of sound poets. As it is the case for other avant-garde literary movements, experiment with sound has always entailed departing from the familiar trail; it has required the complicity of a connoisseur audience to complete its message, and an engagement with technology far superior to that of other literary forms. To start with the analysis of sound poetry in America, we have selected the work of Jerome Rothenberg, an artist who has continued to develop state-of-the-art material for the web (he has curated, for example, an excellent virtual exhibition of Ethnopoetry in Ubuweb).

\subsection{JEROME ROTHENBERG}

Jerome Rothenberg's work is a potent fusion of modernity and tribalism which connects avant-garde concerns with the recuperation of the oral tradition of American native cultures and others. An expert in ethnopoetry and a poet himself, his work challenges sound poetry's own pretense at innovation, creating pieces that recuperate poetry's oral and performative dimension through a process that he describes as total 
translation (1981). For example, his translations of the Senecan ${ }^{2}$ "Horse Songs"3 with Frank Mitchell, a Navajo singer, take the listener to a space outside time and place, where historical lineage collapses inside a single moment of perpetual and timeless human chant.

Rothenberg's recuperation of ancient traditions and his theorization of them within the concerns of contemporary sound poetry make us aware of the role of reception in the classification of art, since any text, like his recordings of Vietnamese folk poems, can be conceptually transformed into a sound poem by a listener who does not understand its language. Actually, for Rothenberg, sound poetry's qualities can be identified with the very process of the performance:

Poems performed are poems sounded, where the sounding by the voice or by instruments acting as surrogate voices can bring a new sense of power/empowerment to performers and auditors. The further extensions and transformations of voice move it closer and closer to "the condition of music," to the point where words and syntax the common constituents of language - are obscured, subordinated, or totally abandoned. (“Ubuweb Ethnopoetics: Soundings")

Rothenberg's understanding of poetry recuperates the experiential nature of ritual, a characteristic that pervades much of the poetical experimentation of the 50s and 60s. Works like Allen Ginsberg's "Howl” or Amiri Baraka's "Wailers," which became hymns of a generation, were not exclusively written as performance pieces, but the performative dimension was an important aspect of the work. The poem was no longer treated as an object of asynchronous communication but as a live experience concentrating the literary communication in time and space, which in turn complicated their reproduction and, therefore, made their entry in the literary canon difficult. Rothenberg's use of recording systems to preserve the sound heritage of exotic cultures and their remediation through the total translation process has in fact created a new genre within sound poetry, the performative ethnopoem, which, thanks to projects such as Ubuweb, continues to influence today's creators and digital poets.

\subsection{JOHN CAGE}

The sound poetry of John Cage seems to be located at the opposite end of the historical spectrum, propelled into the future. Nourished by the technological atmosphere of the post-industrial age, the use of the machine, the instrument, or

\footnotetext{
${ }^{2}$ The Seneca are an indigenous group native to North America, they traditionally lived in what is now New York, between the Genesee River and Canandaigua Lake.

${ }^{3}$ To listen to "Horse Songs"at Ubuweb follow this link:

http://ubumexico.centro.org.mx/sound/rothenberg_jerome/horse_songs/Rothenberg-Jerome_HorseSongs_01.mp3.
} 
rather the lack of it, became a source of inspiration intimately connected with the very mode of production of sound pieces. Three key concepts became ubiquitous during the period in which Cage was composing his sound work: the irruption of noise as a rebellion against bourgeois representational art, chance as a compositional aid and repetition as a technique to denaturalise the endless reproducibility of consumerist art. Exponents of concrete music and poetry, and artists of the Happening and Fluxus movement, continued to expand the performative aspect of their musical and poetic pieces so greatly as to accept all kind of sounds as potentially artistic material. Composition was decided by chance and the binary language of noise and silence became the basic musical component. Many concrete poems became sound poems when the need to perform them live arose, and many concrete music pieces exerted a powerful influence in the work of sound poets; it became fertile soil for the hybrid experiments of Yoko Ono, Laurie Anderson, William S. Burroughs, Dick Higgins, Gregory Whitebread, or bpNichol, to name just a sample of artists that also became practitioners of sound poetry.

In this context, 4'33', John Cage's most famous piece, is a landmark in musical experimentation and, through its simplicity, allowed both chance and performativity to take center stage. "For any instrument or combination of instruments," the musical score only instructs the performer not to play his instrument, and to remain 4 minutes and 33 seconds in silence. The piece was not the silence itself but all the noises the audience could hear from their surroundings at that specific moment. Cage's experimentation with aleatoric composition, based on the creation of unexpected effects by pure luck, aligns him with an artistic current that runs deep within sound poetry experimentation. In his "Lecture on Nothing," a sort of aesthetic manifesto, Cage explicitly announces that he has nothing to say, therefore meaning is redundant, an empty category: "I have nothing to say ... and I am saying it ... and that is poetry ... as I need it” (109). 


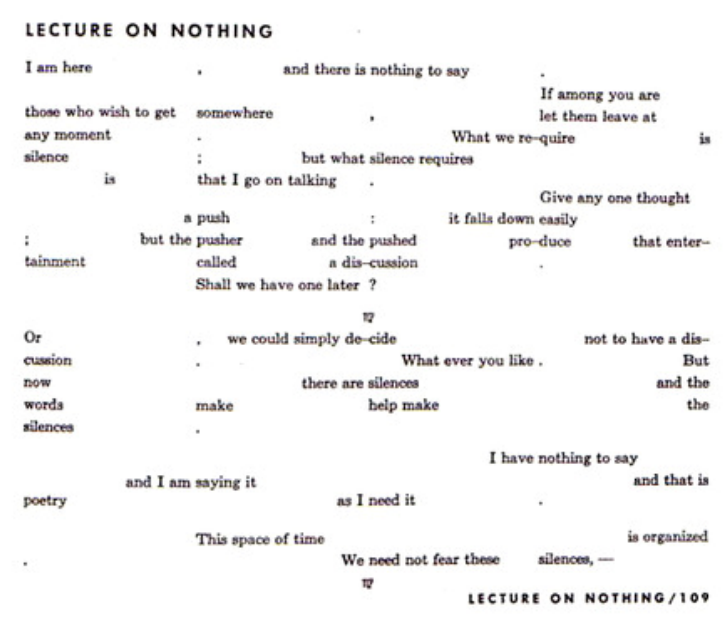

Fig. 3: John Cage, “Lecture on Nothing”, 1961.

Poet Kenneth Goldsmith has actually compared Cage with Thoreau for his ability to detect the sign of the times and transmit it in simple terms:

The beauty of it all is that Cage need do so little -nothing, really- to make this turning of our minds happen. He just opens the window, turns on his tape recorder. Like Thoreau, Cage is a master at simply noticing things. (2009: 286)

"This turning of our minds" to which Goldsmith refers alludes to this sudden awareness that we need to rethink our relation with language; language has become manipulated to such an extent that it has lost all capacity to truly move us, to connect us with the world and with ourselves, that we need to dig at the roots of nonsense, silence, everyday language to discover how we really use and are defined by language. This realization will trigger in Cage the need to record the sounds of life, without the intervention of an author, to obtain a work that is neither self-conscious nor self-assertive. These objectives will become the credo for conceptual poets of the twenty-first century, like Kenneth Goldsmith himself and Christian Bök, who will challenge the Romantic poetic tenets of creativity and authorship.

Since we cannot say anything truly new, why bother making our own creations? Technoculture during the late 70s, and 80s continued to develop this idea with the assistance of recording technology, synthesizers and computers, leaving its mark in plunderphonics and the unoriginality movement in poetry. As we will see, Christian Bök's work is also indebted to Cage, whom he cites as a precedent, together with Perec, Warhol and Bruce Andrews, of a kind of conceptual poetry that tries to 
"disavow the lyrical mandate of self-concious self-assertion in order to explore the readymade potential of uncreative literature” (Bök 2014).

\subsection{JACKSON MAC LOW}

Our third selection of seminal sound poetry practitioners is Jackson Mac Low, a key figure whose poetic experiments with sound will become essential references for today's sound poets and performers. Perhaps one of the most interesting aspects of his poetry is the extensive use he made of repetition. A technique that is going to be shared by many of the poets analysed further on, especially by Tracie Morris. On the one hand, he uses repetition like Gertrude Stein, both to create meaning - though usually in an oblique, indirect manner-, and to investigate how meaning is created, pondering on the relationship between meaning and sound. On the other hand, he uses repetition, in a more Duchampian way, to wonder about the idea of originality and to prove that repetition can bring with it something new.

A good example of his technique is a piece called "Phone," in which the theme of unrequited love is mediated by a technology that substitutes face-to-face contact: the phone. As he himself explains, "Phone" is not really a poem but "a series of poems [...] which consist of a spontaneous poem and ten variations on it" (Mac Low 1978). The majority of the variations consist of what could be called a distortion of the first poem. The words and sounds of the first poem appear again but this time they do not follow any kind of syntactic or semantic rule, becoming rather senseless. Hence, there is a long stretch of time during which "Phone" loses its semantic and grammatical meaning, turning thus from a lyrical poem about love and the pain of not being corresponded, to a more purely Dadaist sound poem, made out of the sheer juxtaposition of a variety of words, sounds and noises. The fact that the poem represents a kind of phone conversation serves the author to investigate how technology affects communication. As it is made manifest in the poem, some technological devices which have been designed to facilitate communication, such as the telephone, alter at the same time our capacity both to produce and perceive sound. As a consequence, we have become ever more detached from our own voices. In this piece, the poet's voice itself no longer sounds merely human but rather mechanical, thus hinting at the process of dehumanization we are suffering due to the extensive use of the new technologies in our everyday lives.

Jerome Rothenberg, John Cage and Jackson Mac Low dealt with subjects and applied sound techniques that prepared the way for subsequent generations of North American sound and digital poets, such as the importance of primitive languages, and the role of the listener as coauthor (Rothenberg), of silence and of its total absence, of unoriginal and uncreative writing (Cage), of the deconstructive and reconstructive 
power of repetition, the new technologies' influence on communication and the process of dehumanization (Mac Low).

\section{GOING DIGITAL: THE POSTHUMAN PHASE IN NORTH AMERICAN SOUND POETRY.}

Another strand of sound poets is composed of blunt technophiles who, before the existence of the Internet, were already deeply immersed in electronic machinery. Without these devices, it would have been difficult to integrate digital technology in poetical composition with the maturity shown by contemporary digital poets. In the 60s and 70s of the twentieth century, artists like Steve Reich, Charles Amirkhanian, Glenn Gould, Charles Dodge, Charles Morrow, John Giorno, Richard Kostelanetz and Alvin Lucier were experimenting with the possibilities offered by tape recording editing and computer sound synthesis. Many of the effects introduced by these artists have been further developed by succeeding digital sound artists.

The machine becomes the new protagonist: sometimes a co-producer of the piece, others a new musical instrument or voice, always offering a new game space open to experimentation. It is symptomatic of this human-machine interaction, for example, Kostelanetz's account of Steve Reich's chance discovery of the process of letting two identical loops go gradually in and out of phase with each other. Reich, a musician exploring modular variation, had been playing with voice recordings of a Pentecostal preacher for one of his pieces, when due to mechanical imprecision, two identical cuts that were playing in unison moved gradually out of synchrony and then back into unison (Kostelanetz 1980: 11). This serendipitous effect became the core of his new piece, "It's Gonna Rain" (1965), emphasizing both the content of the piece and the limits of the tape recorder.

Another piece deconstructing the notion of machine-perfect reproduction of sound is Alvin Lucier's "I Am Sitting in a Room" (1970), which begins with the artist reading a prose statement which is recorded on tape. This recorded version is then played in the same space in which the original statement was pronounced and rerecorded, the process is repeated over a long sequence. The piece is constructed with the succession of recorded and re-recorded versions of the same statement, which progressively degenerate making the language less and less audible, as the distortion of the original statement increases.

Other experiments by Kostelanetz included recycling written and then recorded material to produce sound pastiche and collage, reproducing sound works that were the replica of his own visual texts. A very rich groundwork for sound experimentation opened with the use of computer assisted speech synthesis, as in the work of Charles Dodge or Charles Morrow. For the first time, all the components of a voice (its pitch, speed, loudness, timbre, etc.) could be mathematically identified and altered independently of the others. So, for example, you could increase the speed of the vocal articulation without altering the pitch. 
At the end of the 70s, sound poetry had become a genre in itself but its survival, development, dissemination and archiving was threatened by its very essence: its ephemerality and unavailability. This situation has been partially overturned with the arrival of digital technology, thanks to which a vast collection of sound art has been recuperated and made accessible through the web. Digital technology has become an all-encompassing tool for the creation, manipulation, archiving, distribution, and reproduction of sound. However, as digital artist will also make apparent, this technology also faces its own limitations, such as the very endurance of the medium due to varying bandwidths, information overload, the ever growing need for storage space, the instability of the network, and the rapid obsolescence of its software and hardware.

Digital technology and its effect on poetical composition is the central feature of the posthuman phase in North American sound poetry, and it will inform the work of poets working for the screen and beyond. We will discuss the work of digital poet Jim Andrews, conceptual poet Christian Bök, and performer Tracie Morris.

\subsection{JIM ANDREWS}

Jim Andrews, today a seminal digital poet, began to interest himself in technology and literature in the 80s while hosting a literary radio show in Victoria, Canada. He came across the work of audio artists, like Gregory Whitehead, Helen Thorington, and Susan Stone, who were doing interesting work better suited to the radio than just reading a print poem. After producing his own sound pieces for the radio, he became interested in computers and studied computer science and mathematics.

Unsurprisingly, his work can be accessed on the Internet, namely through a magazine entitled Vispo Langu(im)age: Interactive, Visual, and Sound Poetry by Jim Andrews. In it we can read the author's introduction to his poetry:

You discover alternative approaches to poetry in just about all this work, attempts to synthesize arts, media, and fields such as programming and mathematics or music and recorded sound. As well as attempts to write of the poetics of such practice. It's about putting it all together, connecting, staying human, discovering the nature of our altered humanity and language so that we can address life with fresh insight and communicative power. (Andrews 2001.)

Andrews began creating visual digital poetry but he later recuperated the sound dimension, combining both genres in what he called his "poetics of synthesis" (Andrews 2001). As we shall see, in many of Jim Andrews' pieces his interest in visual poetry, Concrete and Lettrist experiments, fuses with his fascination with programming and music. In his introduction to Nio, an interactive audio piece that fuses both the strategies of visual and sound poetry, Andrews comments on how the 
digital medium also has its preferences, "letters have more character than words" (2001), visually they are easily manipulated to create beautiful forms, and they also occupy less memory. Commenting on his use of sound he recalls:

It was a way into things that cannot be said in words but sometimes needs saying. Written words and sentences do not have easy access to the primal or the harmonic/dissonant reveries of pure sound or the meaningful repetition, variance, trance, and pattern of the drum. (2001)

Thus, the deconstruction of the word initiated by futurist and Dadaist poets has gained new impetus in sound digital poetry, partially motivated as Andrews has pointed out by the medium's own idiosyncrasy. Andrews' work shows a progressive evolution towards higher linguistic abstraction, as his pieces "The Idea of Order at Key West Reordered," "Enigma $\mathrm{n}^{2 \text { " }}$ and "Oppen do Down" testify: moving from the deconstruction of Wallace Stevens' versification -through cuts in mid-attack or decay, loops and rearrangement of the poem's fragmented recording of Stevens'

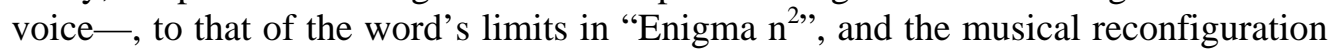
of sound patterns in "Oppen do Down" —an example of his "vismu" or visual music.

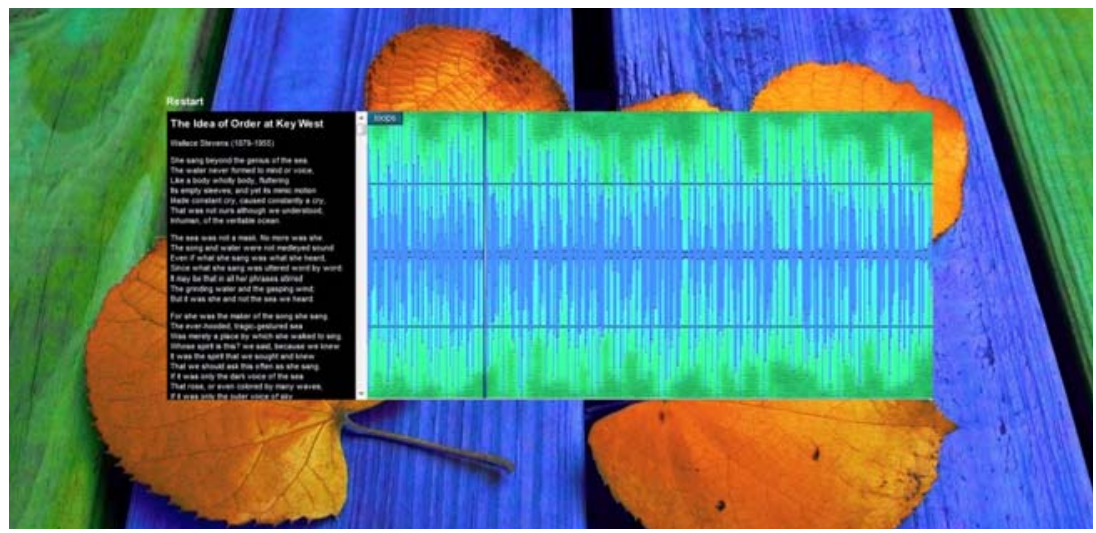

Fig. 4: “The idea of order at Key West Reordered” by Jim Andrews. 


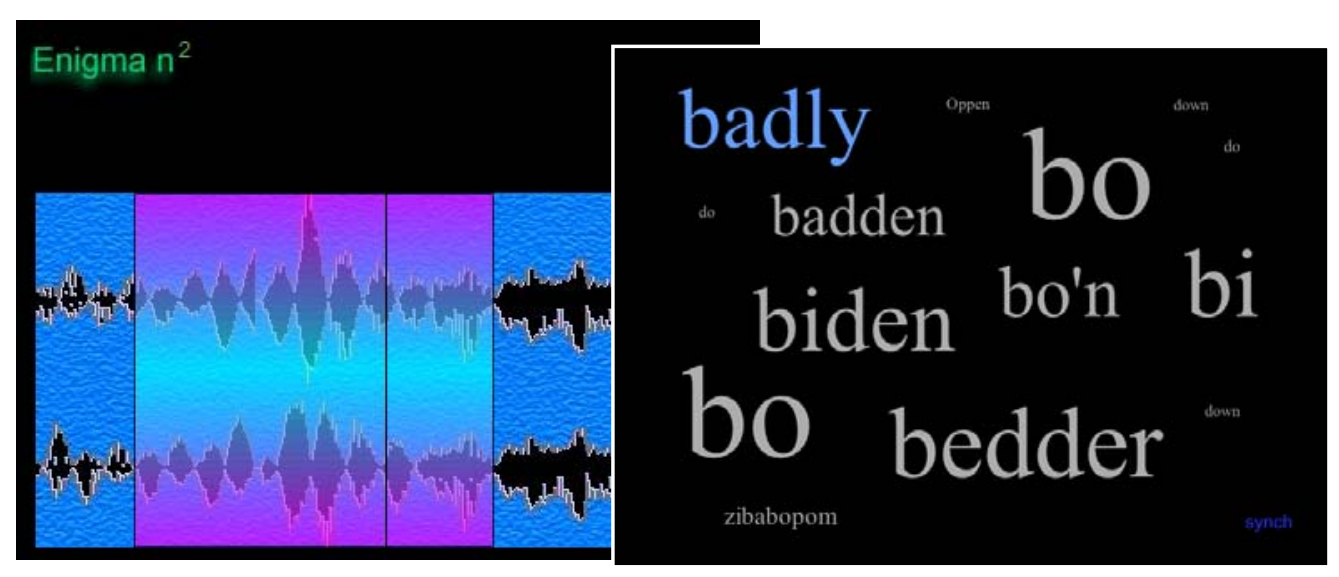

Fig. 5 and 6: “Enigma n"” and “Oppen do Down” (2000) by Jim Andrews.

In all of his pieces, the reader/listener is responsible for the poem's unique and unrepeatable unfolding by interacting with the work. For example, in "Oppen do Down," the reader becomes the player of an atypical musical instrument that allows the user to select loops of five-second duration with a singing voice uttering similar sounds to those graphically represented on the screen. The reader can stack up to eight different layers when multiple "words" are selected and synchronize them using the blue "synch" sign in the lower right corner. This piece proposes a new arbitrary relation between grapheme and phoneme, departing from normalized spelling and spatial formatting, triggering the reader's curiosity and playfulness (Flores 2010). Andrews also rewires the connection between different North American literary traditions and digital poetry, from the Modernist homage implicit in "The Idea of Order at Key West Reordered" to the digital remediation of Hippies' rituals in "F8MW9".

"F8MW9" is a piece created in collaboration with poet Margareta Waterman, who is in charge of the audio and glyphs, while Jim Andrews developed the concept, did the programming and design. It is an interactive piece which allows the reader/listener to manipulate Margareta's voice by means of an invented language, as a drawing with strange signs unfolds or hides from view. This piece fuses elements from both visual and sound poetry: the glyph mysticism finds its mirror in the mystery of the voice and the strange language used, which turns out to be an instance of glossolalia or speaking in tongues, as she confirms in the interview that accompanies the piece. Margareta recounts her experiences living in a commune and how they experimented with initiation rituals, and with an ancient religious practice: just letting the self disappear, freely expressing nonsense as a relieving process. She describes her work as unintentional, both her glyph painting and glossolalia. 
As in Jerome Rothenberg's curating work of American Shakers' ritual practices as a form of visual poetry, Andrews' digital piece F8MW9 calls attention to another ancient ritual deeply immersed in voicing nonsense as a form of sound experimentation and psychic liberation.

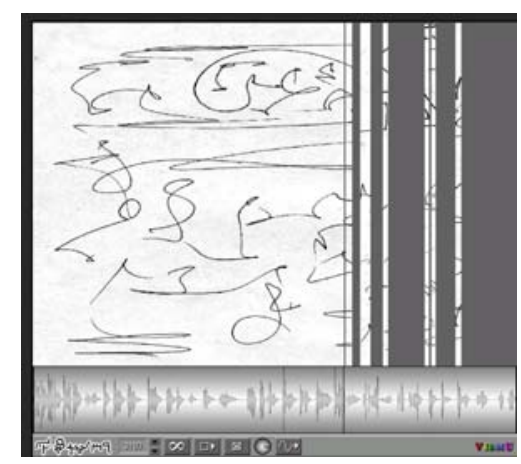

Fig. 7: F8MW9: Interactive Sound Poetry with Margareta Waterman.

Jim Andrew's work adds cyberculture features to the list of standard practices of his predecessors: mainly interactivity and synaesthesia. On the one hand, you need some digital literacy to be able to interact, that is, to understand, explore, and interpret the message in Andrews' creations. On the other, you can no longer dissociate completely image and sound, but you need to listen to images, as in his letter songs, and read sound patterns as new reading strategies that can help you extricate some meaning out of the piece.

\subsection{CHRISTIAN BÖK}

A true product of cyberculture that has nevertheless intentionally remained low-tech is Canadian artist Christian Bök who, instead of actually using digital technology, opts for incarnating the machine in his performances of excerpts from one of his most famous compositions, The Cyborg Opera. In the same way that Marinetti's onomatopoeic poetry responded to the emerging technology of prewar Europe and the sound of war machines during the First World War, The Cyborg Opera, especially such parts as "Mushroom Clouds"4 or "Motorized Razors,"” responds to

\footnotetext{
4 To listen to Christian Bök's "Mushroom Clouds" follow this link: http://mediamogul.seas.upenn.edu/pennsound/authors/Bok/Studio-111/Bok-Christian_05_MushroomClouds_UPenn_4-20-05.mp3).

5 To listen to Christian Bök's “Motorized Razors" follow this link: http://media.sas.upenn.edu/pennsound/authors/Bok/Segue-2001/Bok-Christian_09_Motorized-Razorsfrom-Cyborg-Opera_Segue_NY_5-19-01.mp3).
} 
the saturated and highly technological background sound of our modern society. In his work, Bök explores electronic music as a form of inspiration for the poet of our times, in as much as jazz drove the poets of the 50s and 60s. As he himself explains in his essay "When Cyborgs Versify," "jazz for me has nevertheless become a nostalgic, if not an antiquarian, paradigm. We have already created a poetic version of this older, improved form, but we cannot readily imagine a poetic cognate for a newer, techno beat" (2009:133). Actually, he uses techno music, a genre born in Detroit, as the source of inspiration not only for his rhythm but for his language as well. In some parts of this poem, Bök is trying to compose in a language understandable to machines, rather than human beings, an attempt akin to that of the Russian futurist poet Khlebnikiov when he tried to render or mimic the language of both gods and birds in his "supersaga" Zangezi. This is perhaps most noticeable in his poem "Synth Loops"6 where Bök is using a new, non-human language, made up of sounds similar to those that would be produced by an electronic machine. By so doing, he seeks "to redefine the performer as either a species of mechanic or a species of engineer - a "multiplied man," whose rapport with industrial mechanisms might provide a model” (2009: 131).

Thus, Bök has decided to mimic the machine with his human organs and to alter his language so that it could be understood by machines themselves as a way to reflect about the dehumanizing effect that having a cyborg audience would provoke. Though he never makes clear whether he is warning his audience against this process of dehumanization or rather promoting it. As opposed to other sound poetry practitioners we have analysed whose aim was to search for "a more primitive, libidinal, outburst of organic orality," Bök presents his Cyborg Opera as a critical reaction opposed to "the more 'theurgical' tradition" of Modernism (2009: 130). The fact that he is trying to make his voice sound machinic, instead of using some technological devices for it, also conveys the idea that producing a sound organically does not make it more natural, disrupting the boundary between what is natural and what is not.

However, what differentiates Christian Bök from many other artists who have been producing beatbox pieces from the $80 \mathrm{~s}$ and $90 \mathrm{~s}$, is that, unlike the majority of beatboxers who consider themselves to be musicians, he claims to be a poet, which, together with the fact that his work is called Opera, demonstrates his iconoclastic attitude. One must not forget that the Operatic genre is considered one of the highest artistic and cultural expressions, and he is reducing it to "a sequence of non-sense, inspired by the acoustic ambience of the videogame Super Mario Bross by Nintendo" (Bök 2009: 135). Thus, he is directly and openly attacking the hierarchies that have

\footnotetext{
${ }^{6}$ To listen to Christian Bök’s “Synth Loops” follow this link:

http://mediamogul.seas.upenn.edu/pennsound/authors/Bok/Studio-111/Bok-Christian_07_SynthLoops_UPenn_4-20-05.mp3).
} 
been created, and which still persist, in the art industry of the Western world, something that is common to many of the poets discussed in this chapter.

\subsection{TRACIE MORRIS}

Coming from the slam poetry scene in New York, Tracie Morris' performance of her work "Africa(N)" - included in the album Crosstalk: American Speech Music - is another good example of the transformation digital technology has exerted in the work of American poets. Morris' piece mixes the cadence of Afro-American speech with the imitated disturbances of digital transmission. She turns herself into a deranged cyborg, both by the repetitive and destructive effect of African history and by the dehumanizing effect of technology. The fragmented, jumbled, rhythmical repetition allows the sentence "It all started when we were brought here as slaves from Africa" to acquire a deeper, superposed dimension of meaning.

By inhabiting and improvising within one sentence, Morris releases the physicality of words, plays with sonic associations, and funnels the referential residue of language into more visceral, more estranging and ethical functions. Familiar speech sets in motion something similar to glossolalia by way of accent, slur, stutter, backtracking, striation and telescoping tempo. (Hume 2006: 4)

Her deconstruction of language reminds us of Jackson Mac Low, as she starts from a comprehensible first sentence that is progressively distorted, as if she were reproducing in her performance a piece of sound poetry that had been previously recorded, cut, remixed full of loops and slippages. This is actually the thought that first comes to mind when one accesses Morris' piece for the first time through the web. One thinks that it is a manipulated video recording; instead, it is the poet herself who is, physically instead of digitally, manipulating her own voice. Thus, watching her performance live brings into focus a new relationship between orality and aurality, between what she orally produces and what we aurally perceive. As Christine Hume has described it, "[t]his open display of the procedural nature of language allows a rare simultaneity of intricate apprehensions that seem more available to the ear than to the eye” (Hume 2006: 12). However, as in Mac Low's pieces, there is no relish in highly abstracted conceptualizations, in language destabilization, in absolute chaos and nonsense for its own sake, but in a very poignant defamiliarization of language that cannot leave anybody indifferent. Morris' performance encompasses the listener in its rhythms and inevitably forces him to find a mental representation for a physical pain and a psychological horror that cannot be expressed with words, to end the statement with a second part that is never delivered, and that propels the audience abruptly into the present. 
What has become apparent so far is that digital technology has revolutionized our understanding of aesthetic practices to such an extent that cyberculture may be considered a new aesthetic paradigm applicable to much of the cultural products of the last two decades of the twentieth century and the beginning of the twenty-first.

\section{CONCLUSION}

Reading North American sound poetry from the perspective of the digital age, one inevitably discerns the strokes of its peculiar history and mix of influences: from European avant-gardes, sifted by the revival of experimentation brought about by the Beats, the Fluxus and Concrete Movements in the 60s, the Afro-American influence in rap, hip-hop and other forms of speech music, and the effects of the new media ecology installed by digital recording systems and the Internet. We can also conclude that North American sound poetry owes as much to the avant-garde movements of sound experimentation as to its most primitive roots: a mixture or crossroads where many different influences coalesce, and which should be studied in more detail in order to configure the field of North American sound poetry: African musical and ritualistic heritage, Native Indian poetry, incantations, Shamanic practices, the musical exploration of social and religious experimenters, together with the work of avant-garde multi-media artists, electronic music and sound experimentation, electronic poetry, polypoetry and sound theatre. Often the status of sound poetry as a new medium rather than an intermedium is questioned, since North American artists tend to combine sound poetry with other, more conventional, artistic endeavours, therefore generic distinctions are frequently blurred and sound poetry resources are mixed with other forms of art and aesthetic interests. This rich eclecticism challenges categories, producing sound poems that are at the same time contemporary and primitive, a sedimentation of sound layers at once ephemeral and surprisingly resilient to the passing of time. But this is not an experimental art based on the security of a historical model, but a lineage of alternative modes of artistic and human expression.

At a time in which "all values become comparable but subtly subordinate to the well-being of the art establishment," in which "artists exclude the representation of disorder and the defeat of the imaginary," when "what is produced now is no longer an agitation but an assent" (Celant 1977: 1), sound poetry retains its edge, its capacity to subvert the status quo, and to question the naturalization processes which have turned us into consumers rather than citizens. Not in vain has sound poetry long renounced to confound sound art with decoration for the ear or to deprive music from its capacity to generate change and discussion.

We can also contend that a significant portion of avant-garde literature in North America is not coming out of publishing houses, but of recording studios and the Internet, as Mendi and Keith Obadike argue in their presentation of the album 
Crosstalk: American Speech Music - a compilation of speech-based music by various composers, poets, visual artists and DJs, which includes poet Tracie Morris' Africa(n), together with other pieces by musicians such as "ElectroPrayer 5.0.," in which the drummer and sound artist Guillermo E. Brown rhymes in an invented language. The use of recurrent strategies when it comes to sound is the common thread that connects artists from all these different traditions, unveiling similar sensitivities and concerns.

One of the most common of such practices is the extrication of meaning from human speech using a variety of defamiliarization effects. As we have seen, several artists use repetition as a way to emphasize such defamiliarizing effect, a deviation from the everyday use and context in which the utterance would be found. As a child plays with language, repeating words endlessly, making their end meet the beginning, composing different words by cutting them up and mixing them, altering their intonation, etc., so do sound artists play with their raw material. Those games reveal the texture, the materiality, and also the malleability of language; they expose the structures upon which meaning is made, such as silence or the space between words, rhythm patterns, contrasts.... Another common procedure is the manipulation of the human voice, which sometimes is the original source, the raw material, but others it is revealed as only an illusion. Artists play with our expectations, modulating the human sounds along a spectrum with two poles: human/non-human, and introducing other binary oppositions in the middle: human/animal, male/female. Artists also use computers or musical instruments to mimic the human voice, or use the human voice as if it were a mere instrument or machine. Most works also expose the musical quality of language, which once deprived of its semantic qualities, continues to communicate emotions through its intrinsic sound characteristics, especially through its rhythm. Speech sounds are treated as musical notes that can be permutated, dislocated, reproduced....

As it becomes apparent in digital sound pieces the participation of the listener in the experience is crucial. It is up to the reader's interpretive abilities to discover unexpected effects, to go along with the game proposed, and be able to let go of our need to interpret everything and enjoy the sounds, or just switch off out of boredom. The medium is the massage. Yet, we should not be lulled into banality, but rather find our way among the debris of our technological Babel towers, and, who knows, probably tuning our ears to develop a close listening of the surreptitious effects of sound, rather than search for ultimate meaning, can save our life.

\section{REFERENCES}

Andrews, Jim (September 2001). "Nio and the Art of Interactive Audio for the Web," Vis(p)o. <http://vispo.com/nio/The_Art_of_Interactive_Audio.htm> (Accessed 6 May 2015). 
Attali, Jacques. NOISE: The Political Economy of Music (1985). Theory and History of Literature, Volume 16. Brian Massumi (trans.). London and Minneapolis: U of Minnesota $P$.

Bök, Christian (2009). When Cyborgs Versify. In Perloff, Marjorie and Craig Dworkin, eds., 129-141.

Bök, Christian (July 12, 2014). Conceptual Poetics: Christian Bök and Kenneth Goldsmith. Lecture at the Contemporary Arts Museum in Houston. $<$ https://www.youtube.com/watch?v=D667k70AHo> (Accessed 6 May 2015).

Cage, John (1973). Silence: Lectures and Writings (1961). Middletown: Wesleyan UP.

Celant, Germano (1977). The Record as Artwork: From Futurism to Conceptual Art. Fort Worth, TX: The Fort Worth Art Museum.

Chopin, Henri (1967). Why I am the Author of Sound Poetry and Free Poetry. Ubuweb. Sound Papers. <http://www.ubu.com/papers/chopin.html> (Accessed 6 May 2015).

Flores, Leonardo (2010). Typing the Dancing Signifier: Jim Andrews' (Vis)poetics. Ph.D. Dissertation. http://drum.lib.umd.edu/bitstream/1903/10799/1/Flores_umd_0117E_11445.pdf> (Accessed 6 May 2015).

Goldsmith, Kenneth (2009). Postlude: I love speech. In Marjorie Perloff and Craig Dworkin, eds., 285-289.

Higgins, Dick (1980). A Taxonomy of Sound Poetry. Ubuweb. Sound Papers. $<$ http://www.ubu.com/papers/higgins_sound.html> (Accessed 6 May 2015).

Hume, Christine (Fall 2006). Improvisational Insurrection: The Sound Poetry of Tracie Morris. Contemporary Literature 47(3): 415-439.

Kostelanetz, Richard (1980). Text-Sound Art: A Survey. In Kostelanetz, Richard, ed., $<$ http://www.ubu.com/papers/kostelanetz.html> (Accessed 6 May 2015).

Kostelanetz, Richard, ed. (1980). Text-Sound Texts. New York: William Morrow and Company. Ubuweb. (Accessed 6 May 2015).

Mac Low, Jackson (January 26, 1978). Phone. Public Access Poetry. $<$ http://www.youtube.com/watch?v=JLWujEmqwgM\&list=PLkJ3tHaZAzpLt_hp BA6ga2Xg0iZK3PNd9> (accessed 6 May 2015).

McCaffery, Steve (1978). Sound Poetry: A Survey. In McCaffery, Steve and bpNichol, eds., Ubuweb (Accessed 6 May 2015).

McCaffery, Steve and bpNichol, eds. (1978). Sound Poetry: A Catalogue. Underwich Editions, Toronto. Ubuweb (Accessed 6 May 2015).

McLuhan, Marshall (1964). Understanding Media: The Extensions of Man. New York: McGraw-Hill.

Obadike, Mendi and Keith (2008). Crosstalk: Blurred Boundaries in American Speech Music. Blacknetart.com, New York.

$<$ http://blacknetart.com/Crosstalk_oct08_liner.htm> (Accessed 6 May 2015). 
Perloff, Marjorie and Craig Dworkin, eds. (2009). The Sound of Poetry/the Poetry of Sound. Chicago and London: The U of Chicago P.

Perloff, Nancy (2009). Sound Poetry and the Musical Avant-Garde: A Musicologist Perspective. In Perloff, Marjorie and Craig Dworkin, eds., 97-117.

Rothenberg, Jerome (1981). Total Translation: An Experiment in the Translation of American Indian Poetry. Pre--Faces \& Other Writings, New York: New Directions.

<http://www.ubu.com/ethno/discourses/rothenberg_total.html> (Accessed 6 May 2015).

Rothenberg, Jerome. Ubuweb Ethnopoetics: Soundings. Ubuweb. $<$ http://www.ubu.com/ethno/soundings.html> (Accessed 6 May 2015).

Sayre, Gordon M. (Winter 2013). The Oxymoron of American Pastoralism. Arizona Quarterly: A Journal of American Literature, Culture, and Theory. 69(4): 1-23.

Scheese, Don (2002). Nature Writing. The Pastoral Impulse in America. New York: Routledge. 